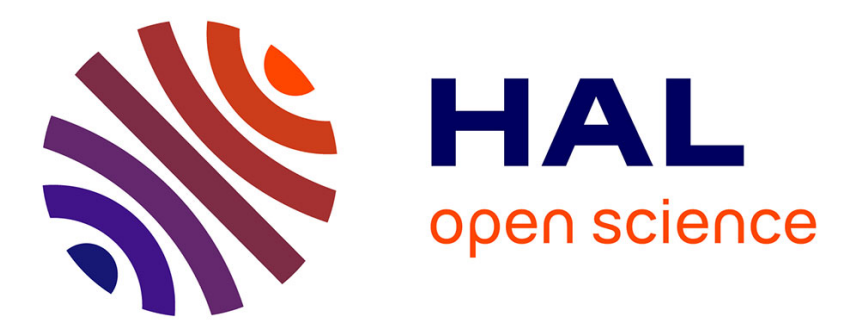

\title{
Role of reversal incoherency in reducing switching field and switching field distribution of exchange coupled composite bit patterned media
}

Thomas Hauet, E Dobisz, S Florez, J Park, B Lengsfield, B.D. Terris, O. Hellwig

\section{To cite this version:}

Thomas Hauet, E Dobisz, S Florez, J Park, B Lengsfield, et al.. Role of reversal incoherency in reducing switching field and switching field distribution of exchange coupled composite bit patterned media. Applied Physics Letters, 2009, 10.1063/1.3276911 . hal-01345308

\author{
HAL Id: hal-01345308 \\ https://hal.science/hal-01345308
}

Submitted on 13 Jul 2016

HAL is a multi-disciplinary open access archive for the deposit and dissemination of scientific research documents, whether they are published or not. The documents may come from teaching and research institutions in France or abroad, or from public or private research centers.
L'archive ouverte pluridisciplinaire $\mathbf{H A L}$, est destinée au dépôt et à la diffusion de documents scientifiques de niveau recherche, publiés ou non, émanant des établissements d'enseignement et de recherche français ou étrangers, des laboratoires publics ou privés. 


\title{
Role of reversal incoherency in reducing switching field and switching field distribution of exchange coupled composite bit patterned media
}

\author{
T. Hauet, ${ }^{\text {a) }}$ E. Dobisz, S. Florez, J. Park, B. Lengsfield, B. D. Terris, and O. Hellwig \\ San Jose Research Center, Hitachi Global Storage Technologies, 3403 Yerba Buena Rd., San Jose, \\ California 95135, USA
}

(Received 1 October 2009; accepted 3 December 2009; published online 29 December 2009)

\begin{abstract}
Model exchange coupled composite media, namely $[\mathrm{Co} / \mathrm{Pd}]_{5} / \mathrm{Pd}(\mathrm{t}) /[\mathrm{Co} / \mathrm{Ni}]_{3} / \mathrm{Co}$ multilayers, deposited onto prepatterned substrates have been investigated for potential use in bit patterned recording. Optimizing the thickness of the Pd interlayer allows decreasing the switching field $\left(\mathrm{H}_{\mathrm{C}}\right)$ and switching field distribution $\left(\sigma_{\mathrm{SFD}}\right)$ while maintaining thermal stability. The dependence of the remanent coercivity on the external field angle indicates that the gain in $\mathrm{H}_{\mathrm{C}}$ and $\sigma_{\mathrm{SFD}}$ originates from the incoherent magnetization reversal introduced by slightly decoupling the hard and soft multilayer stacks. This tendency is confirmed by further reductions in $\mathrm{H}_{\mathrm{C}}$ and $\sigma_{\mathrm{SFD}}$, when inserting another $\mathrm{Pd}$ interlayer within the hard $[\mathrm{Co} / \mathrm{Pd}]_{5}$ stack. (C) 2009 American Institute of Physics.

[doi:10.1063/1.3276911]
\end{abstract}

Bit patterned recording (BPR) is a leading candidate to extend the densities in magnetic data storage beyond those achievable by conventional continuous perpendicular magnetic recording (PMR) based on granular media. BPR involves a lithographically patterned media, where each magnetic island corresponds to a single bit. At remanence, each discrete island maintains a single domain state with its uniform magnetization aligned to a well defined uni-axial anisotropy axis (commonly perpendicular to the disk). The thermal stability of a BPR magnetic bit is given in the macrospin approximation by the product $\mathrm{K}_{\mathrm{u}} \mathrm{V}$, where $\mathrm{K}_{\mathrm{u}}$ is the magnetic anisotropy energy density and $\mathrm{V}$ is the volume of one island. The bits are considered thermally stable for $K_{u} V>60 k_{B} T$, where $\mathrm{k}_{\mathrm{B}}$ is the Boltzman constant and $\mathrm{T}$ is the temperature. Increasing the areal density implies decreasing V. However, any loss in $\mathrm{V}$ needs to be compensated for by an increase in $\mathrm{K}_{\mathrm{u}}$ in order to maintain a proper thermal stability. But the maximum anisotropy is limited by the maximum field that the write head can provide in a hard disk drive. Therefore, improving both thermal stability and writability of bit patterned media (BPM) is an important issue for reaching areal densities higher than $1 \mathrm{~Tb} / \mathrm{in}^{2}$.

Another critical issue for implementing BPM is that the switching field distribution (SFD), i.e., the bit-to-bit variation in coercive field needs to be narrow enough to secure exact addressability of individual predefined bits without overwriting adjacent bits. The SFD has the two following main components: the dipolar interactions between neighboring islands within the array and the so-called intrinsic SFD of each individual island. ${ }^{1,2}$ Depending on the head field gradient, the head-media spacing and the write-synchronization tolerances, a $\sigma_{\mathrm{SFD}}$ value lower than $1 \mathrm{kOe}$ is required for areal density beyond $1 \mathrm{~Tb} / \mathrm{in}^{2}$, considering a media with a static coercive field of around 5 to $7 \mathrm{kOe}$ (Ref. 3). This value is about two times lower than the $\sigma_{\mathrm{SFD}}$ measured in current PMR media.

While in a single spin approximation, writability, and thermal stability are correlated via $\mathrm{K}_{\mathrm{u}}$, it has been recently demonstrated that an improved PMR writability to thermal

${ }^{a)}$ Electronic mail: thomas.hauet@1pm.u-nancy.fr. stability ratio can be achieved by changing the magnetization reversal mechanism. For instance, incoherent reversal is obtained in exchange-spring or exchange coupled composite (ECC) structures. ${ }^{4,5}$ These heterogeneous systems consist of at least two coupled layers with different anisotropies. During the reversal process, the soft layer (SL) moment starts reversing first and forces the hard layer (HL) moment to follow via the interlayer exchange coupling. The torque or the spring produced by the SL moment allows decreasing the switching field of the HL stack, while conserving thermal stability. A large number of theoretical calculations ${ }^{6}$ and experimental studies have been reported on PMR media. ${ }^{7-9}$ However only very few results can be found for BPR, where thermal stability, writability, and also a very low SFD are required. ${ }^{10}$

In the present letter, we describe ECC type media structures that allow manipulating the reversal mechanism and therefore controlling both, writability, and SFD of BPM. Moreover our experimental results show that the incoherency of the magnetization reversal induced in ECC media is the driving force for reducing both reversal field and SFD.

The samples studied here are $[\mathrm{Co} / \mathrm{Pd}]$ and $[\mathrm{Co} / \mathrm{Ni}]$ multilayers (ML) that have been deposited by magnetronsputtering at 3 mTorr Ar pressure on both flat Si substrates and prepatterned substrates consisting of periodic arrays of Si pillars as described earlier. ${ }^{2,11}$ The full film magnetic properties have been measured using a Quantum Design vibrating sample magnetometer. The magnetic properties of the BPM were explored using the polar magneto-optical Kerr effect (PMOKE) with a wavelength of $633 \mathrm{~nm}$ and a focal spot size of $\sim 20 \mu \mathrm{m} .{ }^{1,11}$ All experiments were performed at room temperature. From measurements on full film samples, we conclude that $\mathrm{Ta} / \mathrm{Pd} /[\mathrm{Co}(2.8 \AA) / \mathrm{Pd}(9 \AA)]_{\mathrm{X}} / \mathrm{Pd}$, with $\mathrm{X}$ ranging from 5 to 8 , are hard MLs with an anisotropy field of $\mathrm{H}_{\mathrm{k}, \mathrm{eff}} \sim 21 \mathrm{kOe}$ and a similar magnetization density at saturation $\mathrm{M}_{\mathrm{S}}=500 \mathrm{emu} / \mathrm{cc}$, whereas $\mathrm{Ta} / \mathrm{Pd} / \mathrm{Co}(1.3 \AA) /$ $[\mathrm{Co}(1.5 \AA) / \mathrm{Ni}(7 \AA)]_{\mathrm{Y}} / \mathrm{Co}(2.8 \AA) / \mathrm{Pd}$ with $\mathrm{Y}$ ranging from 2 to 4 are soft MLs with $\mathrm{H}_{\mathrm{k}, \mathrm{eff}} \sim 5 \mathrm{kOe}$ and $\mathrm{M}_{\mathrm{S}}$ $=700 \mathrm{emu} / \mathrm{cc}$.

In Fig. 1(a), we compare the PMOKE signal measured on three different BPM samples. The first one, a 


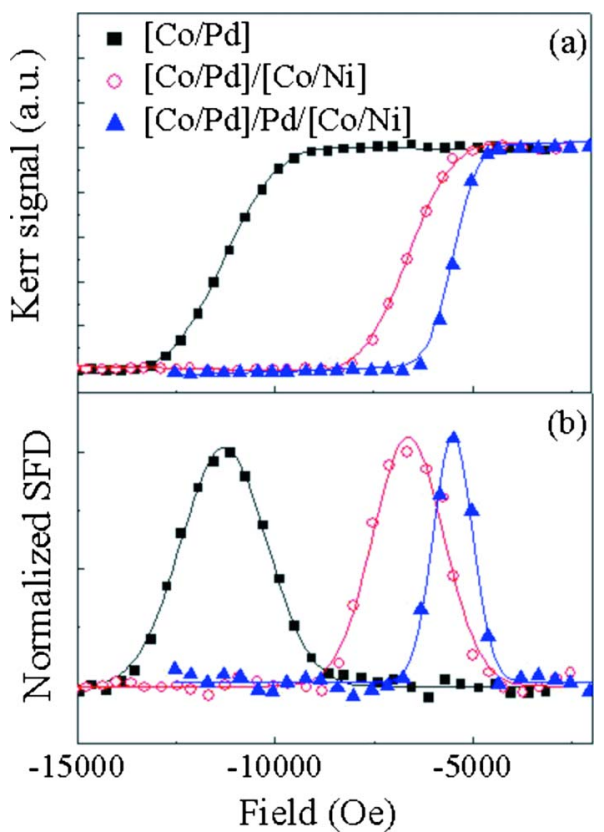

FIG. 1. (Color online) PMOKE reversal curves (a) and their derivatives (b) for a $60 \mathrm{~nm}$ period island array. The lines in (a) and (b) are the corresponding field-integrated Gaussian and Gaussian fits used to extract $\mathrm{H}_{\mathrm{C}}$ and $\sigma_{\mathrm{SFD}}$.

$\mathrm{Ta} / \mathrm{Pd} /[\mathrm{Co}(2.8 \AA) / \mathrm{Pd}(9 \AA)]_{8} / \mathrm{Pd} \mathrm{ML}$ acts as a reference sample. The two other samples are composed of $\mathrm{Ta} / \mathrm{Pd} /$ $[\mathrm{Co}(2.8 \AA) / \operatorname{Pd}(9 \AA)]_{5} / \operatorname{Pd}(\mathrm{t}) / \mathrm{Co}(1.3 \AA) /[\mathrm{Co}(1.5 \AA) /$ $\mathrm{Ni}(7 \AA)]_{3} / \mathrm{Co}(2.8 \AA) / \mathrm{Pd}$, where the $\mathrm{Pd}(\mathrm{t})$ interlayer allows tuning the exchange coupling amplitude between the hard and soft MLs by varying its thickness $t$. The samples shown in Fig. 1 have $\mathrm{t}=0 \AA \AA$ and $\mathrm{t}=10 \AA$. The areal density of the samples presented in Fig. 1 is $180 \mathrm{~Gb} / \mathrm{in}^{2}$, which corresponds to an island period of $60 \mathrm{~nm}$. From the PMOKE curves, we obtain the coercive field $\mathrm{H}_{\mathrm{C}}$ as the average reversal field of the island assembly. We also estimate the absolute SFD, i.e., the standard deviation $\sigma_{\mathrm{SFD}}$ of the reversal field distribution, by fitting a Gaussian to the derivatives of the islands reversal curves [Fig. 1(b)]. Corresponding values extended over a wider range of Pd interlayer thicknesses are summarized in Figs. 2(a) and 2(b). As expected form previous studies on continuous PMR media ${ }^{8}$ and as calculated analytically, ${ }^{12}$ a nonmonotonic evolution of $\mathrm{H}_{\mathrm{C}}$ is observed as the interlayer thickness increases from 0 to $30 \AA$, i.e., as the exchange coupling between the hard and soft part diminishes. In absence of a Pd interlayer, the $[\mathrm{Co} / \mathrm{Ni}]$ and $[\mathrm{Co} / \mathrm{Pd}]$ moments are strongly coupled to each other. As a consequence, the composite structure is expected to behave similarly to a common laminated system with a near coherent reversal as well as a thickness and moment averaged switching field. ${ }^{11}$ As the Pd interlayer thickness $(\mathrm{t})$ increases we create a more decoupled structure and the soft moment can partially reverse under external field, thus inducing a torque onto the hard moment, which lowers the switching field value of the composite system [Fig. 2(a)]. Weakening even more the interlayer coupling, by further increasing t, enable the SL to reverse independently from the HL and the HL switching field increases back toward its intrinsic value. As a matter of fact, for Pd thicknesses higher than $20 \AA$, the PMOKE signal versus field contains two successive reversal steps corresponding to the separate reversal of the SL and HL magnetizations, respectively. The typical behavior as

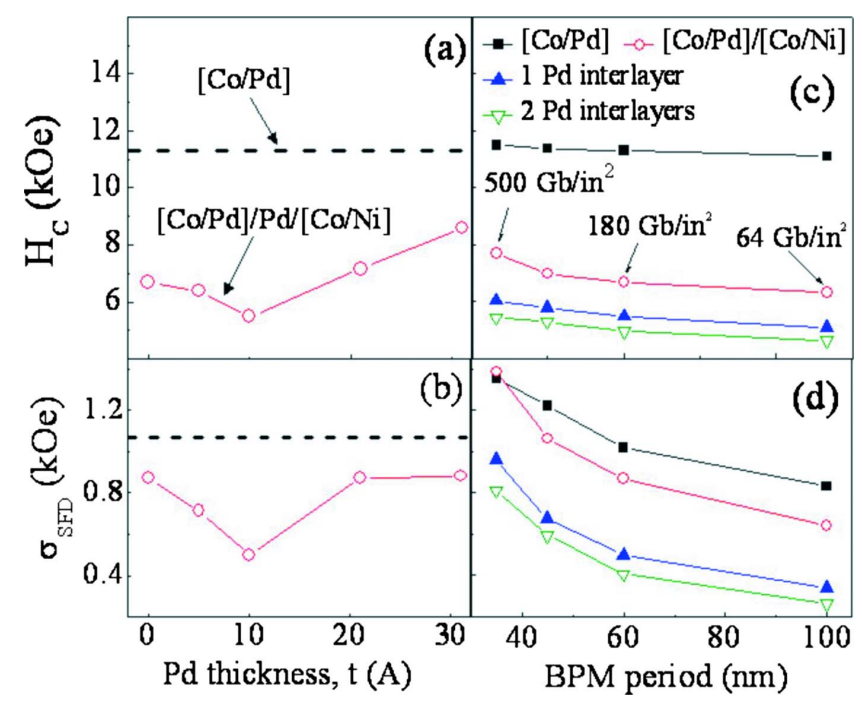

FIG. 2. (Color online) Coercive field $\mathrm{H}_{\mathrm{C}}[(\mathrm{a})$ and (c) $]$ and SFD $\sigma_{\mathrm{SFD}}[(\mathrm{b})$ and (d)] extracted from PMOKE measurements performed on $[\mathrm{Co} / \mathrm{Pd}]_{5} / \mathrm{Pd}(\mathrm{t}) /[\mathrm{Co} / \mathrm{Ni}]_{3} \mathrm{Co}$ as a function of $\mathrm{Pd}$ interlayer thickness $\mathrm{t}[(\mathrm{a})$ and (b) $]$ for $180 \mathrm{~Gb} / \mathrm{in}^{2}$ and performed on $[\mathrm{Co} / \mathrm{Pd}]_{8},[\mathrm{Co} / \mathrm{Pd}]_{5} /[\mathrm{Co} / \mathrm{Ni}]_{3}$, $[\mathrm{Co} / \mathrm{Pd}]_{5} / \mathrm{Pd}(10 \AA) /[\mathrm{Co} / \mathrm{Ni}]_{3}$ and $[\mathrm{Co} / \mathrm{Pd}]_{3} / \mathrm{Pd}(10 \AA) /[\mathrm{Co} / \mathrm{Pd}]_{2} /$ $\mathrm{Pd}(10 \AA) /[\mathrm{Co} / \mathrm{Ni}]_{3}$ as a function of island period $[(\mathrm{c})$ and $(\mathrm{d})]$. The dashed lines in (a) and (b) indicate the value for a $[\mathrm{Co} / \mathrm{Pd}]_{8}$ reference sample.

shown in Fig. 2(a) for an island period of $60 \mathrm{~nm}$ was observed for a variety of densities. In Fig. 2(c) we summarize the $\mathrm{H}_{\mathrm{C}}$ values of $[\mathrm{Co} / \mathrm{Pd}]_{8}, \quad[\mathrm{Co} / \mathrm{Pd}]_{5}[\mathrm{Co} / \mathrm{Ni}]_{3}$, and $[\mathrm{Co} / \mathrm{Pd}]_{5} / \mathrm{Pd}(10 \AA) /[\mathrm{Co} / \mathrm{Ni}]_{3}$ for arrays with period (areal density) of $100 \mathrm{~nm}\left(64 \mathrm{~Gb} / \mathrm{in}^{2}\right), 60 \mathrm{~nm}\left(180 \mathrm{~Gb} / \mathrm{in}^{2}\right), 45$ $\mathrm{nm}\left(300 \mathrm{~Gb} / \mathrm{in}^{2}\right)$, and $35 \mathrm{~nm}\left(500 \mathrm{~Gb} / \mathrm{in}^{2}\right)$. The $\mathrm{H}_{\mathrm{C}}$ reduction obtained with the ECC structure is independent of areal density. In addition we performed hard axis loop measurements on the corresponding full film structures in order to extract the anisotropy field, i.e., in first approximation the thermal stability, for various Pd interlayer thicknesses. Although the addition of $[\mathrm{Co} / \mathrm{Ni}]_{3}$ to $[\mathrm{Co} / \mathrm{Pd}]_{5}$ reduces its $\mathrm{H}_{\mathrm{k}, \text { eff }}$ from 21 to $18 \mathrm{kOe}$ mainly due to the change in $\mathrm{M}_{\mathrm{S}}$, varying the Pd interlayer thickness does not change the hard axis loop of the ECC structure further. Our results thus confirm that ECC media can be used to reduce the coercive field and the SFD of BPM while maintaining thermal stability.

The behavior of the SFD, $\sigma_{\mathrm{SFD}}$, as a function of the Pd interlayer thickness is shown in Fig. 2(b). A nonmonotonic variation in the SFD is observed with a minimum that is similar to the $\mathrm{H}_{\mathrm{C}}$ behavior in Fig. 2(a). For the present sample series, $[\mathrm{Co} / \mathrm{Pd}]_{5} / \mathrm{Pd}(\mathrm{t}) /[\mathrm{Co} / \mathrm{Ni}]_{3}$, the static dipolar induced component of the SFD does not depend on the Pd thickness $t$, since the $M_{S} V$ per island does not change. Therefore we attribute the observed nonmonotonic variation in SFD to the partial exchange decoupling of the soft and the HL magnetization. ${ }^{13}$ As calculated in Ref. 6, the equivalent gain in SFD for PMR media originates from the fact that the magnitude of the coercivity reduction increases with an increasing difference between the HL anisotropy and the SL anisotropy. ${ }^{12}$ This theoretical explanation is confirmed experimentally here by comparing the SFD of $[\mathrm{Co} / \mathrm{Pd}]_{5} /[\mathrm{Co} / \mathrm{Ni}]_{3}$ and $[\mathrm{Co} / \mathrm{Pd}]_{5} / \mathrm{Pd}(10 \AA) /[\mathrm{Co} / \mathrm{Ni}]_{3}$ samples in Fig. 1(b). Indeed the $\mathrm{H}_{\mathrm{C}}$ reduction for the hardest islands is about $1.8 \mathrm{kOe}$, while for the softest islands it is less than 500 Oe [Fig. 1(b)]. Overall, the ECC system $[\mathrm{Co} / \mathrm{Pd}]_{5} / \mathrm{Pd}(10 \AA) /[\mathrm{Co} / \mathrm{Ni}]_{3}$ shows very promising $\mathrm{SFD}$ 


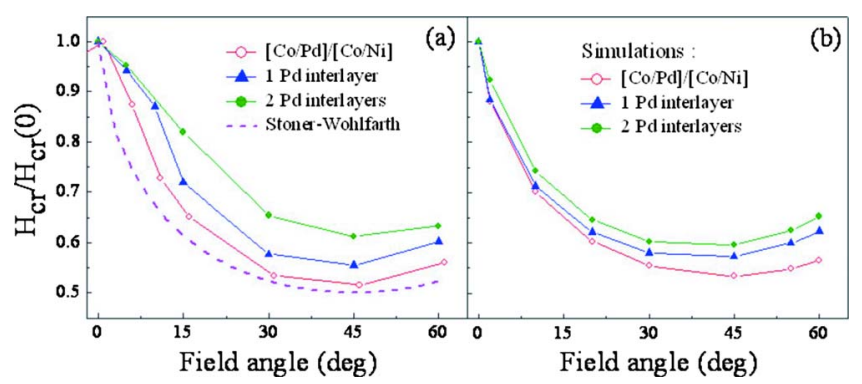

FIG. 3. (Color online) Measured (a) and simulated (b) relative remanent coercivity as a function of applied field angle for a $35 \mathrm{~nm}$ period array composed of $[\mathrm{Co} / \mathrm{Pd}]_{5} /[\mathrm{Co} / \mathrm{Ni}]_{3}, \quad[\mathrm{Co} / \mathrm{Pd}]_{5} / \mathrm{Pd}(10 \AA) /[\mathrm{Co} / \mathrm{Ni}]_{3}$, and $[\mathrm{Co} / \mathrm{Pd}]_{3} / \mathrm{Pd}(10 \AA) /[\mathrm{Co} / \mathrm{Pd}]_{2} / \mathrm{Pd}\left(\begin{array}{ll}10 & \AA\end{array}\right) /[\mathrm{Co} / \mathrm{Ni}]_{3}$. The dashed line in (a) is the Stoner-Wohlfarth curve.

values $\left(\sigma_{\mathrm{SFD}}=960 \mathrm{Oe}\right.$ at $500 \mathrm{~Gb} / \mathrm{in}^{2}$ for a switching field $\mathrm{H}_{\mathrm{C}}=6 \mathrm{kOe}$ ) when compared with existing BPR theoretical requirements. ${ }^{3}$

To emphasize the gain obtained by tuning the vertical exchange coupling in ECC media, we fabricated another sample, namely $[\mathrm{Co} / \mathrm{Pd}]_{3} / \mathrm{Pd}(10 \AA) /[\mathrm{Co} / \mathrm{Pd}]_{2} / \mathrm{Pd}(10 \AA) /$ $[\mathrm{Co} / \mathrm{Ni}]_{3}$, where a second $\mathrm{Pd}$ interlayer was inserted inside the $[\mathrm{Co} / \mathrm{Pd}]_{5} \mathrm{HL}$. As shown in Figs. 2(c) and 2(d) this allows further decreasing $\mathrm{H}_{\mathrm{C}}$ as well as the SFD. In-plane hard axis hysteresis loops reveal that the new ECC structure including two Pd interlayers has the same anisotropy field as the $[\mathrm{Co} / \mathrm{Pd}][\mathrm{Co} / \mathrm{Ni}]$ and $[\mathrm{Co} / \mathrm{Pd}] / \mathrm{Pd} /[\mathrm{Co} / \mathrm{Ni}]$. Therefore, we can conclude that the introduction of a second exchange-break layer into the ECC structure allows further reduction of $\mathrm{H}_{\mathrm{C}}$ and $\sigma_{\mathrm{SFD}}$, while the effective volume and thus thermal stability is only affected very little (if at all) due to the slight decoupling within the HL stack. ${ }^{14}$

Finally we investigated the angular dependence of the remanent coercivity in order to reveal the enhancement of incoherency in the reversal process when adding one and then two Pd interlayers. ${ }^{9}$ The relative remanent coercivity $\mathrm{H}_{\mathrm{CR}} / \mathrm{H}_{\mathrm{CR}}(0)$, where $\mathrm{H}_{\mathrm{CR}}(0)$ is the remanent coercivity at zero angle, measured for $35 \mathrm{~nm}$ island period is plotted as a function of the field angle in Fig. 3. Zero angle corresponds to a field applied perpendicular to the ML interfaces. The theoretical angular dependent coercivity of the different samples was simulated using a three-spin generalization of the macrospin potential surface model developed by Bertram and Lengsfield. ${ }^{12}$ Each $[\mathrm{Co} / \mathrm{Pd}]_{3},[\mathrm{Co} / \mathrm{Pd}]_{2}$, and $[\mathrm{Co} / \mathrm{Ni}]_{3}$ ML corresponds to a single spin, characterized by its $\mathrm{H}_{\mathrm{k} 1}$ and $\mathrm{M}_{\mathrm{S}}$ values. A variation in the exchange coupling constant in between the spins stands for the variation in Pd interlayer thickness. For instance, we consider $\mathrm{J}=1.5 \times 10^{-6} \mathrm{erg} / \mathrm{cm}$ and $0.4 \times 10^{-6} \mathrm{erg} / \mathrm{cm}$ for $t_{P d}=0$ and $10 \AA$, respectively. In this simulation, the coercivity is determined by utilizing a second-order optimization procedure to locate the stable points on the potential energy surface as a function of the applied field. As presented in Fig. 3(b), the trends of the experimental data shown in Fig. 3(a) when adding Pd interlayers are reproduced by the calculation. In Fig. 3(a), the $\mathrm{H}_{\mathrm{CR}} / \mathrm{H}_{\mathrm{CR}}(0)$ variation in the $[\mathrm{Co} / \mathrm{Pd}]_{5} /[\mathrm{Co} / \mathrm{Ni}]_{3}$ sample is similar to the variation calculated for the Stoner-Wohlfarth type reversal. ${ }^{15}$ The relative remanent coercivity ratio has a minimum close to 0.5 when the field is applied at a $45^{\circ}$ angle. The small discrepancy with the Stoner-Wohlfarth case may already result from a partial incoherency in the reversal process. As one and then two Pd interlayers are inserted, the minimum $\mathrm{H}_{\mathrm{CR}} / \mathrm{H}_{\mathrm{CR}}(0)$ value increases up to 0.56 and 0.61 , respectively. The same evolution has been obtained for the other densities and is well reproduced by the calculations [Fig. 3(b)]. Such gradual shallowing of the $\mathrm{H}_{\mathrm{CR}}$ angular dependence has also been reported in PMR exchange-spring media and reveals a vertical incoherency in the reversal process. ${ }^{9}$ The angular dependence of the switching field is nevertheless far from the Kondorsky-type behavior, ${ }^{9,16}$ since the magnetic layers in our ECC system are too thin and too hard to allow the nucleation of a vertical domain wall within the depth of the ML.

In summary, we have studied ECC type media deposited onto prepatterned Si pillars with periods from $35 \mathrm{~nm}$ to 100 $\mathrm{nm}$. By increasing the Pd thickness $\mathrm{t}$ in the hard/Pd/soft $[\mathrm{Co} / \mathrm{Pd}]_{5} / \mathrm{Pd}(\mathrm{t}) /[\mathrm{Co} / \mathrm{Ni}]_{3} \mathrm{MLs}$, i.e., slightly decreasing the interfacial exchange coupling, the coercivity $\left(\mathrm{H}_{\mathrm{C}}\right)$ and the SFD $\left(\sigma_{\mathrm{SFD}}\right)$ can be tuned while maintaining thermal stability. The addition of a second Pd interlayer inside the HL allows further reduction in both $\mathrm{H}_{\mathrm{C}}$ and $\sigma_{\mathrm{SFD}}\left(\sigma_{\mathrm{SFD}}=800\right.$ Oe for $\mathrm{H}_{\mathrm{C}}=5.5 \mathrm{kOe}$ ). However if the Pd interlayer coupling within the HL stack becomes too weak, then thermal stability may start to be affected. ${ }^{14}$ The observed reductions in SFD are promising for implementing BPR based on ECC media into hard disk drives. Finally, we have experimentally demonstrated that the gain provided by the ECC structure originates indeed from a more incoherent vertical reversal mechanism.

${ }^{1}$ O. Hellwig, A. Berger, T. Thomson, E. Dobisz, H. Yang, Z. Bandic, D. Kercher, and E. E. Fullerton, Appl. Phys. Lett. 90, 162516 (2007).

${ }^{2}$ T. Thomson, G. Hu, and B. D. Terris, Phys. Rev. Lett. 96, 257204 (2006).

${ }^{3}$ M. E. Schabes, J. Magn. Magn. Mater. 320, 2880 (2008).

${ }^{4}$ R. H. Victora and X. Shen, IEEE Trans. Magn. 41, 537 (2005).

${ }^{5}$ D. Suess, T. Schrefl, S. Fähler, M. Kirschner, G. Hrkac, F. Dorfbauer, and J. Fidler, Appl. Phys. Lett. 87, 012504 (2005).

${ }^{6}$ D. Suess, J. Lee, J. Fidler, and T. Schrefl, J. Magn. Magn. Mater. 321, 545 (2009).

${ }^{7}$ J. P. Wang, W. Shen, J. Bai, R. H. Victora, J. H. Judy, and W. L. Song, Appl. Phys. Lett. 86, 142504 (2005)

${ }^{8}$ A. Berger, N. Supper, Y. Ikeda, B. Lengsfield, A. Moser, and E. E. Fullerton, Appl. Phys. Lett. 93, 122502 (2008).

${ }^{9}$ T. Thomson, B. Lengsfield, H. Do, and B. D. Terris, J. Appl. Phys. 103, 07F548 (2008).

${ }^{10}$ R. Sbiaa, K. Oo Aung, S. N. Piramanayagam, E.-L. Tan, and R. Law, J. Appl. Phys. 105, 073904 (2009).

${ }^{11}$ O. Hellwig, T. Hauet, T. Thomson, E. Dobisz, J. D. Risner-Jamtgaard, D. Yaney, B. D. Terris, and E. E. Fullerton, Appl. Phys. Lett. 95, 232505 (2009).

${ }^{12}$ H. N. Bertram and B. Lengsfield, IEEE Trans. Magn. 43, 2145 (2007).

${ }^{13}$ One could argue that the dipolar field influence during the magnetization reversal is enhanced by the incoherency of the reversal but the details of this dynamical SFD component is beyond the scope of our current study. Thus we include this effect in the intrinsic variation due to the change of reversal mechanism.

${ }^{14}$ H. J. Richter, E. Girt, and H. Zhou, Appl. Phys. Lett. 80, 2529 (2002).

${ }^{15}$ E. C. Stoner and E. P. Wohlfarth, Philos. Trans. R. Soc. London A240, 599 (1948).

${ }^{16}$ E. Kondorsky, J. Phys. (Moscow) 2, 161 (1940). 